\title{
State-Specific Trends in Preterm Delivery: Are Rates Really Declining Among Non-Hispanic African Americans Across the United States?
}

\author{
Anjel Vahratian, PhD, MPH, ${ }^{1,4}$ Pierre Buekens, MD, PhD, ${ }^{2}$ \\ and Greg R. Alexander, ScD, $\mathrm{MPH}^{3}$
}

\begin{abstract}
Published online: 13 December 2005
Objectives: This study sought to examine state-specific trends in preterm delivery rates among non-Hispanic African Americans and to assess whether these rates are influenced by misclassification of gestational age. Methods: The sample population consisted of singleton nonHispanic White and non-Hispanic African-American infants born in 1991 and 2001 to U.S. resident mothers. For both time periods, state-specific and national preterm delivery rates were calculated for all infants, stratified by infant race/ethnicity. Next, birth-weight distributions within strata of gestational age were studied to explore possible misclassifications of gestational age. Lastly, state-specific and national preterm delivery rates among infants who weighed less than $2,500 \mathrm{~g}$ were separately computed. Results: National analyses showed that the frequency of preterm delivery increased by $15.8 \%$ among non-Hispanic Whites but declined by $10.3 \%$ among non-Hispanic African Americans over the same period. For both subgroups, a bimodal distribution of birth weights was apparent among preterm births at 2831 weeks of gestation. The second peak with its cluster of normal-weight infants was more prominent among non-Hispanic African Americans in 1991 than in 2001. After excluding preterm infants who weighed 2,500 g or more, the national trends persisted. State-specific analyses showed that preterm delivery rates increased for both subgroups in 13 states during this period. Of these 13, 6 states had a number of non-Hispanic African-American births classified as preterm that were apparently term births mistakenly assigned short gestational ages. Such misclassification was more frequent in 1991 than in 2001 and inflated 1991 rates. Conclusion: There is heterogeneity in state-specific preterm delivery rates. Such differences are often overlooked when aggregate results are presented.
\end{abstract}

KEY WORDS: bias (epidemiology); birth certificates; blacks; gestational age; infant; premature.

\section{INTRODUCTION}

\footnotetext{
${ }^{1}$ Department of Obstetrics and Gynecology, University of Michigan, Ann Arbor, MI.

${ }^{2}$ Department of Epidemiology, Tulane University, New Orleans, LA.

${ }^{3}$ Department of Maternal and Child Health, University of Alabama at Birmingham, Birmingham, AL.

${ }^{4}$ Correspondence should be addressed to Anjel Vahratian, $\mathrm{PhD}$, MPH, Department of Obstetrics and Gynecology, University of Michigan at Ann Arbor, L4000 Women's Hospital, 1500 E. Medical Center Drive, Ann Arbor MI 48109-0276; e-mail: amv@med.umich.edu.
}

Published data suggest that national preterm delivery rates for non-Hispanic African Americans are declining in the United States (1-3). Between 1990 and 1997, the singleton preterm delivery rate decreased by $10 \%$ among non-Hispanic AfricanAmerican women, but increased by $11 \%$ among nonHispanic White women (1). The reasons for such trends are not fully understood, but some studies suggest that these findings could be due to errors in recording the date of a woman's last menstrual 
period, which may have resulted in misclassification of gestational age and thus preterm status $(1,2)$.

A recent analysis of data from North Carolina electronic livebirth files showed that at first glance, preterm delivery rates for non-Hispanic African Americans declined from $17.9 \%$ in 1989 to $16.5 \%$ in 1999 (4). However, the authors further examined the distribution of birth weights by gestational age and saw that at 28-31 weeks' gestation, the distribution of birth weights was distinctly bimodal. A bimodal distribution of birth weights among preterm infants strongly suggests misclassification of gestational age (5-7). After excluding preterm infants whose birth weights were $2500 \mathrm{~g}$ or more, the preterm delivery rate for non-Hispanic African Americans actually increased from 1989 to 1999 (8.4 and 8.9\%, respectively). The authors concluded that a number of non-Hispanic African-American births classified as preterm were apparently term births mistakenly assigned short gestational ages. This misclassification inflated 1989 preterm rates in North Carolina.

This analysis prompted us to examine whether the reported national decline in preterm delivery rates among non-Hispanic African Americans was similarly influenced by misclassification of gestational age and whether other states noted similar trends in preterm delivery rates as in North Carolina. Thus, the present study sought to examine the potential for misclassification of gestational age both at the state and national level.

\section{MATERIALS AND METHODS}

For this analysis, we examined data from the 1991 and 2001 United States Natality Files, which were made available by the National Center for Health Statistics. Our sample consisted of singleton non-Hispanic White and non-Hispanic AfricanAmerican infants born in $1991(n=3,091,487)$ and $2001(n=2,761,876)$. Preterm delivery was the main outcome evaluated, defined for the purposes of this analysis as a livebirth at 20-36 weeks of gestation. Infant race/ethnicity was determined by both the reported race of the mother and her Hispanic origin status.

We first calculated state-specific and national preterm delivery rates for the overall population, stratified by infant race/ethnicity. State-specific preterm delivery rates were based on maternal state of residence. The primary measure used to determine gestational age in vital statistics, as determined by the National Center for Health Statistics, is the interval between the first day of the mother's last menstrual period and her date of birth (8). If this information was missing or implausible, the clinical estimate of gestational age was used in its place and was defined broadly as the number of weeks of gestation based on the clinical evidence available. The National Center for Health Statistics reported that the clinical estimate was used as the period of gestation for $4.9 \%$ of births in 2001 (8). Unfortunately, information was not available to the authors on how often the clinical estimate was used for the period of gestation in 1991.

Next, we calculated national birth-weight distributions within strata of gestational age to explore possible misclassifications of gestational age. Misclassification of gestational age among normal birth weight infants can be detected by a bimodal distribution of weights among preterm infants (5-7). Thus, as a means of excluding infants whose gestational ages were potentially misclassified, we also calculated state-specific and national preterm delivery rates among infants who weighed less than $2,500 \mathrm{~g}$. Similarly, we identified the 50th percentile (median) of birth weight for each week of gestation and for both non-Hispanic Whites and non-Hispanic African Americans. As an alternate approach to excluding preterm infants who weighed 2,500 g or more, we calculated national preterm delivery rates among infants who fell at or under the 50th percentile of birth weight. This approach would exclude nearly all of those cases where the gestational age is presumed to be lower than it should be given the infants' recorded birth weight.

Lastly, we used the Wilcox-Russell approach to separate national birth weight distributions of all births into predominant and residual distributions $(9,10)$. The predominant distribution is bell shaped and can reflect the birth weight distribution of term births. The residual distribution represents births in the lower tail of the curve outside the predominant distribution and thus the proportion of small and preterm births. Together, the predominant and residual distributions of birth weight allow for insights into gestational age without requiring calculated gestational age data. This approach avoids misclassification of gestational age by using the frequency distribution of birth weight.

All analyses were performed by using Statistical Analysis Software (SAS), version 8.1 (SAS Institute Inc., Cary, North Carolina). 


\section{RESULTS}

\section{National Trends}

For non-Hispanic Whites, the preterm delivery rate increased from $7.6 \%$ in 1991 to $8.8 \%$ in 2001 (Table I). The preterm delivery rate declined in nonHispanic African Americans, from 17.4\% in 1991 to $15.6 \%$ in 2001 . Most of the changes in preterm delivery rates for both subgroups occurred in the moderately preterm category (32-36 weeks) (data not shown).

Birth weight distributions within strata of gestational age showed that at 28-31 weeks gestation, the distribution of birth weights was distinctly bimodal for both populations (Fig. 1). The second peak was more prominent in 1991 than in 2001 among the infants weighing $2,250-2,750 \mathrm{~g}$. In contrast, the first peak was larger in 2001 for the nonHispanic African-American infants who weighed $1,250-1,500 \mathrm{~g}$.

A bimodal distribution of birth weights among preterm infants strongly suggests misclassification of gestational age (5-7). Errors in measuring gestational age may be due to factors such as menstrual cycle irregularities, early vaginal bleeding during pregnancy, or inaccurate recall of when the last menstrual period started (11-14). Unfortunately, we were unable to assess the validity of these possible explanations because this information is not recorded in vital records. When we excluded preterm infants who weighed 2,500 $\mathrm{g}$ or more (as a means of excluding infants whose gestational ages were potentially misclassified), we found that the national preterm delivery rate for non-Hispanic African Americans declined from 1991 to 2001 (8.5 and $8.0 \%$, respectively). Preterm delivery rates for non-Hispanic Whites increased over the same period (2.9 and 3.3\%, respectively). Similarly, we excluded birth weights above the 50th percentile of birth weight and found essentially the same trends as our adjusted rates (data not shown).

While the national preterm delivery rate appears to be declining in non-Hispanic African Americans but increasing among non-Hispanic Whites, we were interested in whether this trend persisted among the small, preterm births. Thus, we computed the residual distribution of birth weight proposed by Wilcox and Russell $(9,10)$. This analysis of the birth weight distributions indicated that the residual distribution of birth weight remained con- stant for non-Hispanic African Americans and increased for non-Hispanic Whites over the two time periods (Table II). From 1991 to 2001, the residual distribution for non-Hispanic Whites increased from $1.8 \%$ to $2.1 \%$. Among non-Hispanic African Americans, the residual distribution generally remained constant at $4.2 \%$ over the same period. Thus for non-Hispanic African Americans, the proportion of small, preterm births remained stable from 1991 to 2001.

\section{State-Specific Trends}

For non-Hispanic Whites, the preterm delivery rate increased in 49 states from 1991 to 2001 (declines were noted in New Hampshire and the District of Columbia) (Table I). For non-Hispanic African Americans, there was heterogeneity in the trends. Whereas the national data showed a decline in the preterm delivery rates, state-specific data showed an increase in seven states (Alabama, Alaska, Colorado, Iowa, Nebraska, New Mexico, and West Virginia) from 1991 to 2001. In Oklahoma, the rate remained stable for non-Hispanic African Americans over the same period $(16.3 \%)$. Moreover, the preterm delivery rate in Arizona, Massachusetts, and Mississippi in 2001 remained within a tenth of its 1991 value.

To reduce the potential for bias due to misclassification of infant gestational age, we calculated preterm delivery rates that excluded those preterm infants who weighed 2,500 g or more. Unlike the original analysis, this calculation showed that preterm delivery rates increased for non-Hispanic African Americans in six additional states besides those noted earlier: Arizona, Louisiana, Mississippi, North Carolina, Oklahoma, and South Carolina. In Indiana, the preterm delivery rate remained stable for non-Hispanic African Americans from 1991 to 2001 (7.6\%). Moreover, the preterm delivery rate in Virginia in 2001 remained within a tenth of its 1991 value.

For non-Hispanic Whites, the preterm delivery rate increased in 48 states from 1991 to 2001 . Moreover, the trend of declining preterm delivery rates in New Hampshire persisted after excluding preterm infants who weighed 2,500 g or more $(4.3$ and $2.9 \%$, respectively). In Vermont, the preterm delivery rate in 2001 for non-Hispanic Whites remained within a tenth of its 1991 value. 
Table I. State-By-State Trends in Preterm Delivery Rates (\%)—Overall and After Excluding Preterm Infants Who Weighed 2,500 g

\begin{tabular}{|c|c|c|c|c|c|c|c|c|}
\hline \multirow[b]{3}{*}{ State } & \multicolumn{4}{|c|}{ Non-Hispanic White } & \multicolumn{4}{|c|}{ Non-Hispanic African-American } \\
\hline & \multicolumn{2}{|c|}{1991} & \multicolumn{2}{|c|}{2001} & \multicolumn{2}{|c|}{1991} & \multicolumn{2}{|c|}{2001} \\
\hline & Overall & Revised & Overall & Revised & Overall & Revised & Overall & Revised \\
\hline United States & 7.6 & 2.9 & 8.8 & 3.3 & 17.4 & 8.5 & 15.6 & 8.0 \\
\hline \multicolumn{9}{|l|}{ Southeast } \\
\hline Alabama & 8.7 & 3.4 & 10.9 & 3.9 & 17.9 & 8.4 & 18.2 & 8.8 \\
\hline Arkansas & 9.2 & 3.5 & 9.9 & 3.7 & 19.4 & 9.0 & 17.4 & 8.3 \\
\hline Florida & 8.0 & 3.0 & 9.5 & 3.6 & 17.4 & 7.9 & 15.9 & 7.7 \\
\hline Georgia & 8.1 & 3.2 & 9.3 & 3.7 & 16.9 & 8.0 & 14.6 & 7.8 \\
\hline Kentucky & 8.8 & 3.5 & 10.8 & 4.2 & 17.8 & 8.1 & 16.3 & 7.6 \\
\hline Louisiana & 8.4 & 2.9 & 9.8 & 3.8 & 18.8 & 8.5 & 17.8 & 9.1 \\
\hline Mississippi & 9.5 & 3.5 & 12.0 & 4.2 & 18.8 & 8.2 & 18.7 & 9.1 \\
\hline Missouri & 8.1 & 3.1 & 9.5 & 3.5 & 19.0 & 9.4 & 17.7 & 8.4 \\
\hline N. Carolina & 8.4 & 3.4 & 9.7 & 3.9 & 18.1 & 8.6 & 16.4 & 8.8 \\
\hline S. Carolina & 8.3 & 3.4 & 9.7 & 3.8 & 16.4 & 8.5 & 16.2 & 8.7 \\
\hline Tennessee & 9.2 & 3.7 & 10.9 & 4.4 & 19.3 & 9.6 & 16.3 & 8.6 \\
\hline Virginia & 7.4 & 2.8 & 8.2 & 3.1 & 16.5 & 7.6 & 14.5 & 7.5 \\
\hline W. Virginia & 8.7 & 3.4 & 11.3 & 4.5 & 16.5 & 7.3 & 16.7 & 9.8 \\
\hline \multicolumn{9}{|l|}{ Southwest } \\
\hline Arizona & 8.0 & 3.0 & 9.6 & 3.4 & 15.6 & 7.4 & 15.5 & 7.6 \\
\hline California & 6.9 & 2.4 & 7.2 & 2.6 & 14.8 & 7.1 & 13.2 & 6.2 \\
\hline Colorado & 7.9 & 3.5 & 8.8 & 3.7 & 14.8 & 8.0 & 15.5 & 8.3 \\
\hline Hawaii & 7.1 & 2.6 & 8.2 & 3.4 & 14.4 & 7.5 & 12.9 & 6.6 \\
\hline Kansas & 7.6 & 3.0 & 8.8 & 3.3 & 16.7 & 8.0 & 13.3 & 7.1 \\
\hline Nevada & 8.9 & 3.4 & 9.6 & 3.5 & 19.3 & 9.4 & 16.6 & 7.7 \\
\hline New Mexico & 7.4 & 2.9 & 10.2 & 4.0 & 15.2 & 8.2 & 16.4 & 8.5 \\
\hline Oklahoma & 8.0 & 2.8 & 10.4 & 3.8 & 16.3 & 6.4 & 16.3 & 8.9 \\
\hline Texas & 8.0 & 3.0 & 9.8 & 3.4 & 16.8 & 8.0 & 16.2 & 7.8 \\
\hline Utah & 7.0 & 2.8 & 8.6 & 3.3 & $b$ & $b$ & $b$ & $b$ \\
\hline \multicolumn{9}{|l|}{ Northwest } \\
\hline Alaska & 6.2 & 2.2 & 6.8 & 2.5 & 12.1 & $b$ & 13.5 & $b$ \\
\hline Idaho & 7.1 & 2.8 & 8.3 & 2.9 & $b$ & $b$ & $b$ & $b$ \\
\hline Montana & 6.9 & 2.6 & 8.7 & 3.6 & $b$ & $b$ & $b$ & $b$ \\
\hline N. Dakota & 7.1 & 2.5 & 8.5 & 3.2 & $b$ & $b$ & $b$ & $b$ \\
\hline Nebraska & 6.9 & 2.5 & 8.8 & 3.0 & 14.9 & 7.3 & 15.2 & 7.9 \\
\hline Oregon & 6.8 & 2.3 & 7.5 & 2.6 & 14.3 & 7.4 & 12.2 & 6.4 \\
\hline S. Dakota & 6.8 & 2.6 & 8.5 & 3.1 & $b$ & $b$ & $b$ & $b$ \\
\hline Washington & 6.7 & 2.5 & 7.8 & 2.9 & 13.6 & 6.8 & 11.1 & 5.3 \\
\hline Wyoming & 8.8 & 3.1 & 10.0 & 4.0 & $b$ & $b$ & $b$ & $b$ \\
\hline \multicolumn{9}{|l|}{ Midwest } \\
\hline Illinois & 7.5 & 2.9 & 8.6 & 3.2 & 18.7 & 9.3 & 16.4 & 8.4 \\
\hline Indiana & 7.7 & 2.9 & 9.5 & 3.5 & 16.6 & 7.6 & 15.5 & 7.6 \\
\hline Iowa & 7.2 & 2.8 & 8.6 & 3.0 & 15.7 & 7.3 & 17.4 & 8.5 \\
\hline Michigan & 7.5 & 2.9 & 8.4 & 3.1 & 18.1 & 9.4 & 16.2 & 8.6 \\
\hline Minnesota & 6.4 & 2.3 & 7.5 & 2.9 & 16.2 & 8.9 & 9.6 & 5.1 \\
\hline Ohio & 8.2 & 3.2 & 9.3 & 3.5 & 17.1 & 8.5 & 15.1 & 8.1 \\
\hline Wisconsin & 7.0 & 2.6 & 8.4 & 3.1 & 18.3 & 8.8 & 15.7 & 7.9 \\
\hline \multicolumn{9}{|l|}{ Northeast } \\
\hline Connecticut & 6.3 & 2.6 & 6.6 & 2.8 & 15.2 & 9.2 & 11.8 & 7.0 \\
\hline Delaware & 8.1 & 3.0 & 9.1 & 4.1 & 19.2 & 9.4 & 15.4 & 8.6 \\
\hline D.C & 6.6 & 2.7 & 6.2 & 2.7 & 21.3 & 11.9 & 17.8 & 9.7 \\
\hline Maine & 6.2 & 2.5 & 8.0 & 3.2 & $b$ & $b$ & $b$ & $b$ \\
\hline Maryland & 7.4 & 2.8 & 8.5 & 3.4 & 16.4 & 8.5 & 15.1 & 8.0 \\
\hline Massachusetts & 5.5 & 2.4 & 7.1 & 2.8 & 12.4 & 6.9 & 12.3 & 6.1 \\
\hline New & 8.8 & 4.3 & 7.0 & 2.9 & $b$ & $b$ & $b$ & $b$ \\
\hline Hampshire & & & & & & & & \\
\hline
\end{tabular}


Table I. Continued.

\begin{tabular}{lllllllll}
\hline New Jersey & 6.9 & 2.7 & 7.7 & 2.8 & 17.6 & 9.1 & 15.7 & 8.1 \\
New York & 6.7 & 2.6 & 7.4 & 2.8 & 16.4 & 8.8 & 13.8 & 6.8 \\
Pennsylvania & 7.1 & 2.9 & 8.2 & 3.4 & 18.4 & 9.9 & 15.5 & 8.7 \\
Rhode Island & 6.8 & 2.7 & 7.7 & 3.3 & 15.7 & 8.1 & 14.7 & 7.2 \\
Vermont & 6.8 & 2.7 & 7.1 & 2.6 & $b$ & $b$ & $b$ & $b$ \\
\hline
\end{tabular}

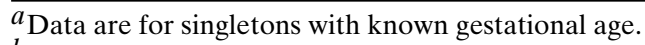

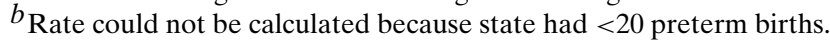

${ }^{c}$ Italic numbers indicate increases in preterm delivery among non-Hispanic African Americans.

\section{DISCUSSION}

The decline in preterm deliveries among nonHispanic African Americans, as reported in earlier studies, appears to have been influenced by misclassification of gestational age. The degree of influence is more noticeable at the state level. In contrast, at the national level the documented trends are likely influenced by populated states such as California, New York, and Texas, as each had declining preterm delivery rates in their non-Hispanic African-American residents.

Furthermore, this study demonstrates that the issue of misclassification of gestational age with respect to trends in preterm delivery rates extends beyond one state. There is heterogeneity in preterm delivery rates in the United States and such differences are often overlooked when we focus our attention broadly on trends at the national level. This study confirms findings from a previous report on trends in preterm delivery in North Carolina (4) and lends support for future publications to take potential misclassification into account when interpreting the data. A consensus about the best methodology to exclude implausible birth weights has yet to be determined. Nevertheless, obtaining unbiased estimates for very low gestational ages is especially crucial from a public health point of view.

Because gestational age estimates are prone to misclassification because of errors in maternal selfreport of the date of the last menstrual period, alternate statistical measures have been developed to provide more accurate birth-weight distributions for gestational age. Approximately 20 years ago, Wilcox and Russell $(9,10)$ proposed the use of predominant and residual distributions of birth weight as an

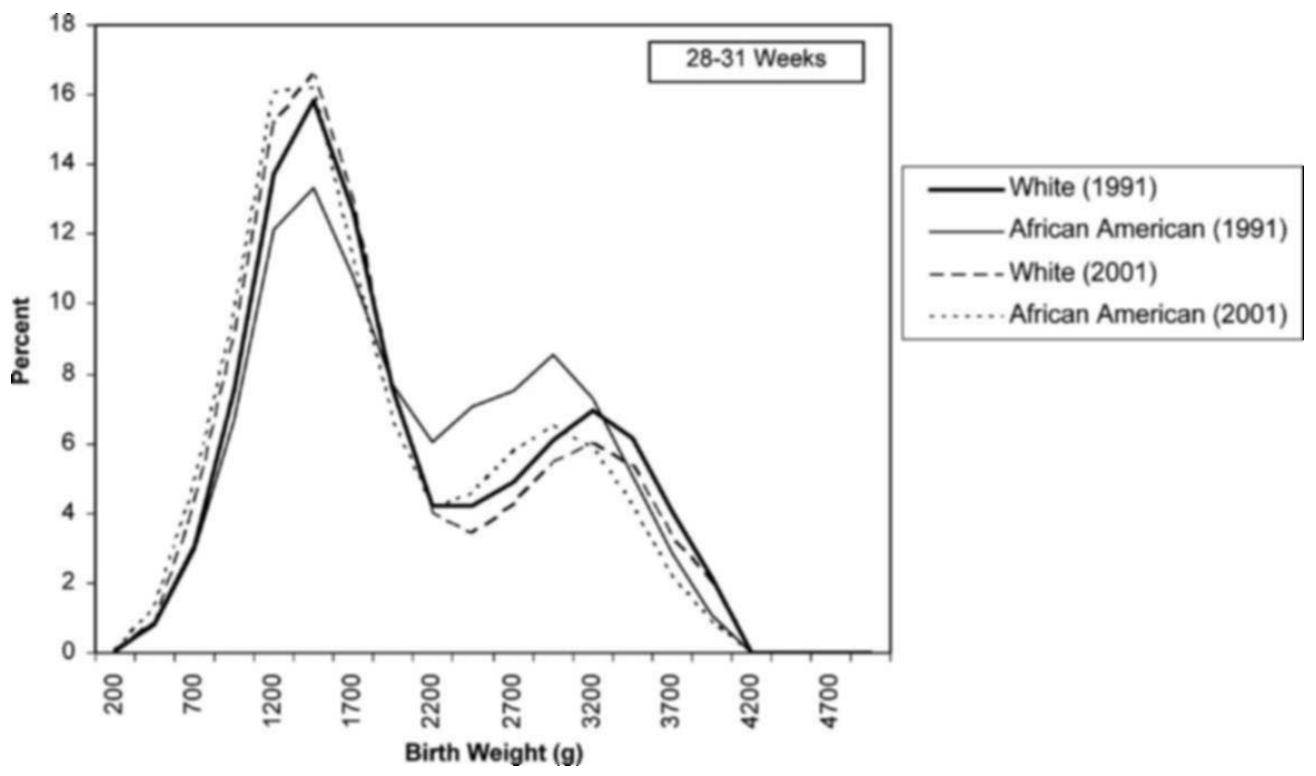

Fig. 1. Birth-weight distribution for non-Hispanic White and non-Hispanic African-American newborns at 28-31 weeks of gestation, United States, 1991 and 2001. 
Table II. Residual and Prominent Distributions of Birth Weight ${ }^{a}$ for non-Hispanic White and non-Hispanic African-American Newborns, United States, 1991 and 2001

\begin{tabular}{|c|c|c|c|c|}
\hline & \multicolumn{2}{|c|}{ Non-Hispanic White } & \multicolumn{2}{|c|}{$\begin{array}{c}\text { Non-Hispanic } \\
\text { African-American }\end{array}$} \\
\hline & $\begin{array}{c}\text { Residual } \\
\text { distribution } \\
\quad(\%)\end{array}$ & $\begin{array}{c}\text { Prominent } \\
\text { distribution } \\
(\mathrm{mean} \pm \\
\left.\mathrm{SD}^{b}, \mathrm{~g}\right)\end{array}$ & $\begin{array}{l}\text { Residual } \\
\text { distribution } \\
\quad(\%)\end{array}$ & $\begin{array}{c}\text { Prominent } \\
\text { distribution } \\
\text { (mean } \pm \\
\text { SD, g) }\end{array}$ \\
\hline 1991 & 1.8 & $3586 \pm 496$ & 4.2 & $3327 \pm 504$ \\
\hline 2001 & 2.1 & $3562 \pm 488$ & 4.2 & $3342 \pm 494$ \\
\hline
\end{tabular}

$a_{\text {Data generated from online program to analyze birth weight }}$ data; accessible at http://eb.niehs.nih.gov/bwt/index.htm.

$b_{\mathrm{SD}}$ standard deviation.

indirect method of presenting information on gestational age without actually using gestational age data. Although the residual distribution does not correspond to the proportion of all preterm births, it does identify those who are at highest risk: small, preterm births. In our analysis, the residual distribution for non-Hispanic Whites increased, but remained stable for non-Hispanic African Americans, from 1991 to 2001. Such trends lend support to the argument that medical and public health interventions aimed at primary prevention of preterm birth remain unsuccessful. However, it is possible that the increase in medical interventions to deliver at-risk fetuses earlier and to produce more multiple births through assisted reproductive technologies may well mask the potential benefit of public health interventions.

In conclusion, this analysis demonstrated that while national preterm delivery rates for nonHispanic African Americans appear on the decline, this trend is less evident at the state level. For 13 states, preterm delivery rates are increasing for both non-Hispanic Whites and non-Hispanic African Americans. Of these 13, 6 states appear to have had a number of non-Hispanic African-American births classified as preterm that were apparently term births mistakenly assigned short gestational ages. Such misclassification appeared to be more frequent in 1991 than in 2001 and inflated 1991 preterm delivery rates in these states, so that it appeared that their rates were declining.

\section{ACKNOWLEDGMENTS}

Dr. Vahratian was supported by the Building Interdisciplinary Research Careers in Women's Health (BIRCWH) program, National Institutes of Health (1 K12 HDO1438).

This research was presented in part at the 18th Annual Meeting of the Society for Pediatric and Perinatal Epidemiologic Research, Toronto, Canada, June 26-27, 2005.

\section{REFERENCES}

1. State-specific changes in singleton preterm births among black and white women-United States, 1990 and 1997. MMWR Morb Mortal Wkly Rep 2000;49:837-40.

2. Preterm singleton births-United States, 1989-1996. MMWR Morb Mortal Wkly Rep 1999;185-9.

3. Demissie K, Rhoads GG, Ananth CV, Alexander GR, Kramer MS, Kogan MD, Joseph KS. Trends in preterm birth and neonatal mortality among blacks and whites in the United States from 1989 to 1997. Am J Epidemiol 2001;154:307-15.

4. Vahratian A, Buekens P, Bennett TA, Meyer RE, Kogan MD, Yu SM. Preterm delivery rates in North Carolina: Are they really declining among non-Hispanic African Americans? Am J Epidemiol 2004;159:59-63.

5. Alexander GR, Himes JH, Kaufman RB, Mor J, Kogan M. A United States national reference for fetal growth. Obstet Gynecol 1996;87:163-8.

6. Arbuckle T, Wilkins R, Sherman GJ. Birth weight percentiles by gestational age in Canada. Obstet Gynecol 1993;81:39-48.

7. David RJ. The quality and completeness of birthweight and gestational age data in computerized data files. Am J Public Health 1980;70:964-73.

8. Martin JA, Hamilton BE, Ventura SJ, Menacker F, Park MM, Sutton PD. Births: Final data for 2001. Natl Vital Stat Rep 2002;51:1-116.

9. Wilcox AJ. On the importance-and the unimportance-of birthweight. Int J Epidemiol 2001;30:1233-41.

10. Wilcox AJ, Russell IT. Birthweight and perinatal mortality. I. On the frequency distribution of birthweight. Int J Epidemiol 1983;12:314-8.

11. Kramer MS, McLean FH, Boyd ME, Usher RH. The validity of gestational age estimation by menstrual dating in term, preterm, and postterm gestations. JAMA 1988;260:3306-8.

12. Guerrero R, Florez PE. The duration of pregnancy [letter] Lancet 1969;2:268-9.

13. Saito M, Yazawa K, Hashiguchi A, Kumasaka T, Nishi N Kato K. Time of ovulation and prolonged pregnancy. Am J Obstet Gynecol 1972;112:31-8.

14. Gjessing HK, Skjaerven R, Wilcox AJ. Errors in gestational age: Evidence of bleeding early in pregnancy. Am J Public Health 1999;89:213-8. 